\title{
EMOTIONAL SELF-AWARENESS AND ETHICAL DELIBERATION
}

Ratio XVIII, March 2005

Michael Lacewing

\begin{abstract}
$\underline{\text { Abstract }}$
How are we to distinguish between appropriate emotional responses that reveal morally salient reasons and inappropriate emotional responses that reflect our prejudices? It is often assumed that reason - considered as distinct from emotion - will make the distinction. I argue that this view is false, and that the process by which emotional responses are vetted involves 'emotional self-awareness'. By this, I mean feeling an emotion, being aware of so doing, and feeling some usually subtle emotional response, often of calm or anxiety, to it, together with a general readiness to feel and acknowledge what emotions one has. Registering and exploring feelings of anxiety that arise in emotional self-awareness helps enable us to detect when emotions and thoughts are inappropriate. Deliberation that is not emotionally open in this way is therefore at an epistemic disadvantage. Furthermore, the attempt to remain unemotional when evaluating one's emotions can be produced or co-opted by anxiety about one's feelings of precisely the kind that indicates one's emotional responses and thoughts are being distorted.
\end{abstract}

There is currently considerable interest in the importance of the emotions to making good ethical decisions. Taking as given the view that emotions are evaluative responses, ${ }^{1}$ how are we to distinguish between 'appropriate' emotional responses that guide us towards what is of real value, towards genuinely morally salient reasons for 
action, and 'inappropriate' emotional responses that reflect our prejudices and hangups? The idea that an emotion is not self-justifying is uncontentious, but it is often assumed that reason - considered as distinct from emotion - will provide the justification. I shall call this position 'intellectualism'.

One can find examples of influential philosophers who find no essential place for emotion in ethical deliberation almost across the ethical board. The exception is virtue ethics, which commonly brings reason and emotion closer together than other theories. Contemporary utilitarianism has developed a sophisticated division between justification and deliberation, and some forms, such as character utilitarianism, advise us not to consider outcomes in a utilitarian fashion when deliberating on right action, since this is likely to lead to a less than optimal result. Nevertheless, utilitarian calculation is still frequently used as a decision procedure in many philosophical examples in works in both theoretical and practical ethics. Utilitarian calculation is usually represented as a method of reasoning with facts, with emotions either explicitly denigrated, or not mentioned. J J C Smart, R M Hare, and Peter Singer, for instance, all argue in this vein. ${ }^{2}$ Kantians, on the other hand, have had little to say on the possible role of emotion in deliberation and the discernment of duty. ${ }^{3}$ The decisive step of applying the test of the Categorical Imperative is supposedly purely rational, though Kantians may grant that awareness of one's emotions may be important for knowing one's maxim, which is central to applying the test correctly. ${ }^{4}$ Intellectualism is also found elsewhere, for example, in works by Jonathan Dancy and Thomas Nagel. ${ }^{5}$

If we accept the view that emotions can track and reveal values and morally salient reasons for action, then some of the views described above are already in trouble for discarding an important source of evaluative information. This argument 
has been made, largely by virtue theorists, and I do not intend to discuss it further. In any case, the point may easily be incorporated by maintaining that reason should attend to, evaluate, and then process or discard the evaluation embodied in the emotion, and continue with its non-emotional deliberation. But how is it that we evaluate the reliability and validity of our emotions? I shall argue that emotion is essentially involved in this process of discovering which emotions are 'appropriate'. If I am right, the problems facing these views, and others similar to them, is far more serious.

In $\S \S$ I-III I argue that the process by which emotional responses are vetted involves further kinds of emotional input. In $\S \S \mathrm{IV}-\mathrm{V}$, I respond to objections, including the objection that emotions can be destructive of deliberation, and that they therefore need to be set aside or suppressed for us to remain 'clear-headed'. However, it is worth saying now that I am not claiming that deliberation is a matter of being swayed by and following emotions wherever they take us; nor is the state of emotional self-awareness that I recommend intended as a kind of substitute for rational thought. My claim is that rational thought is dangerously incomplete without certain types of emotional input. Furthermore, emotional self-awareness should not be taken as equivalent to 'being emotional' (a state that can involve very little selfawareness of any kind); which of course means that I deny that the only alternative to 'being emotional' is being unemotional.

I shall restrict my discussion to deliberation as coming to an ethical judgment about what to do, which I believe is at the core of moral thought, for morality is first and foremost practical. This involves making ethical judgments about the rightness and wrongness about possible states of affairs, actions, etc. If we are not to be hypocritical, our judgments of right and wrong in general should reflect those related 
to our own particular case. In the first instance, the question we each face is 'what it is right for me to do?' - deliberation is first-personal.

\section{$\underline{\text { I. Emotional self-awareness }}$}

If we are to evaluate our emotions during deliberation in the attempt to discover whether they are insightful or misleading, awareness of our emotions is clearly important, for we may feel an emotion without taking note of the fact. One form of self-consciousness about one's emotions is the awareness that one is experiencing an emotion, a conscious registering of the fact of experiencing an emotion. This awareness is not itself affectively tinged, and it is compatible with not really feeling the emotion. Thinking of one's emotions as facts about oneself could be one way of considering emotions in deliberation. As the emotions themselves do not enter into deliberation except as 'facts', it is a form of representation which non-emotional reason might use when evaluating emotions.

There is a second form of self-consciousness of one's emotions which I shall call emotional self-awareness. Emotional self-awareness involves three things: feeling the emotion, being aware of so doing, and, normally, feeling some 'second-order' emotional response to it (the response is 'second-order' in that it is a response to the emotion). To these three, we may add a dispositional fourth: an openness to emotions, a readiness to feel and acknowledge what emotions one has.

The second-order feelings involved in emotional self-awareness are often very subtle, and frequently lie along an axis of psychological tension and calm. I may identify with the emotion and feel sure of it, or feel vaguely uncomfortable, guilty, shameful, or perhaps defensive about it. These feelings of tension, discomfort, anxiety 
or of calm and psychological integrity are distinct from the positive or negative feelings of the emotion that forms the object of self-awareness. I would say we have these second-order feelings in any case, but often fail to identify them; in emotional self-awareness, we can become conscious of them.

I shall argue that emotional self-awareness, not simple 'self-representation' reducing emotions to facts about ourselves - is essential to good deliberation. This response of comfort or discomfort, either immediately or upon reflection, to a firstorder emotion can help inform our evaluations of whether the emotion reveals or distorts the value of its object to us. But I shall first describe the phenomenology more closely to identify just what it is I believe can help in this way.

People can be less or more aware of what it is they feel. Let us take the case of a man who inappropriately feels resentment towards someone else, $\underline{a}$; in fact, he feels resentment because he feels impotent when around a. If he is at least aware of feeling resentful, there are (at least) six states he could find himself in, depending on how self-aware he is:

1. he feels resentment, tinged with anxiety, towards a, but he is not aware that he is feeling anxious in his resentment; however, there is something-it-is-like to experience resentment tinged with anxiety, and his resentment will come across to an acute observer as that of an anxious man;

2. he registers the anxiety overlaying or incorporated in the resentment, but he is uncertain about this identification, and fails to understand the anxiety or its significance;

3. he succeeds in distinguishing anxiety from the resentment, but does not know why he is anxious; he just feels both resentful and anxious; 
4. he understands that he is anxious, in some way, about feeling resentful, or more accurately, anxious in connection with his resentment;

5. he understands the source of his anxiety, relating it to his fear of impotence; if he achieves this, he will also understand his resentment as being related to the same;

6. he is able to acknowledge and integrate his fear of impotence into himself, which lessens the fear to an extent; his resentment towards a, should he still feel it, dissipates whenever it arises.

There is one stage that precedes (1) above, in which resentment is not felt, because the response to the fear of impotence takes the primitive form of a bodily symptom. In such somaticization,

0. the man he does not feel any particular emotion consciously at all, but whenever he is around $\underline{\mathrm{a}}$, he feels nauseous.

This example shows how, if we are aware of feeling anxious in relation to an emotion, we may gain insight into the source of that emotion. But this is a complex matter. I am not claiming, for example, that if one feels discomfort regarding an emotion, this automatically means that it is inappropriate or that it misrepresents its object. Discomfort can be caused by an appropriate, revelatory emotion clashing with my self-image. In either case, though, noticing it is the route into unravelling the emotion and the grounds for the discomfort that accompanies it. In this way, by better understanding the source of our emotions, we may also come to understand the evaluations they contain as misleading or insightful. 
Emotional self-awareness can extend beyond our emotions, to take other mental states and processes as its object. For instance, it can also take the process of deliberation as its object. As deliberation proceeds, it will be marked by emotional responses to the possible options considered, to the thoughts entertained, to the manner or style of the deliberation itself. And these emotional responses will be, or be marked by, similar feelings of tension or its opposite. The deliberation may seem to have become stale, or waspish, or missing the point, or unduly technical, or defensive; or it may feel true, important, expressive, involving, and so on. These emotional responses to the process of deliberation are a part of that process, a feedback mechanism that can help guide the course it takes. In this way, emotional responses are involved in the evaluation of deliberation, an evaluation that is important for how insightful that deliberation is.

It is clear that insightful self-awareness is of help to deliberation. But need it take the affective form I have described? To better answer this question, I shall first expand on some psychological operations that can influence what we feel, and present the argument that emotional self-awareness is necessary for good deliberation in $\S$ III.

\section{$\underline{\text { II. Defence Mechanisms and Emotional Self-Awareness }}$}

Our emotional responses often do not reveal reasons for acting, but are projections of difficulties within ourselves. Some rather simplified examples: homophobics, projecting their own homosexual feelings into homosexuals, respond to homosexuals as though they are a threat, e.g. to the moral fabric of society, while the 'threat', which is to the homophobic's ego-ideal, in fact arises from within the homophobic. Similar issues are at stake in any division of the world into an evil 'them' and a 
righteous 'us', such as the Nazis' view of the Jews. A different example: someone not given a promotion, simply because he was not the best person for the job, may feel resentful of his boss, but come to believe his boss resents or hates him (this neatly provides a rationalization for his lack of promotion, as the worker refuses to recognise his unsuitability for the post). Or again, after a difficult break-up, a man may deny to himself as well as others - that he feels angry or bitter, or indeed that he ever loved the woman he was with. He may not be aware of feeling these feelings.

According to contemporary psychoanalytic theory, these cases are united in two ways. First, they make use of psychological processes that can be useful in other circumstances. For instance, the suppression of feeling involved in the last case can be useful when performing emotionally difficult tasks, such as autopsies. Or again, the projection of our own (good) traits into others can form part of the build-up of trust in healthy relationships; taken to an extreme, it might lead to a less healthy, but still productive, creation of an artistic muse who inspires our creativity. Second, in each case, the processes are used to defend the subject against a painful reality by perverting his or her experience of that reality. When used to this end, we may call the processes 'defence mechanisms'.

Defence mechanisms are activated by painful or unacceptable emotions and desires and seek to prevent them from reaching consciousness. ${ }^{6}$ They make use of mental processes that, using the imagination, operate 'on mental content that represents the cause of anxiety in such a way as to reduce or eliminate anxiety'. (In fact, the processes may operate in relation to any of several painful feelings, including shame and guilt, but I shall focus on anxiety.) This reduction of anxiety is, in such cases, the processes' 'psychic function', ${ }^{8}$ i.e. they occur precisely because they are causally efficacious, via their operations on mental content, in reducing anxiety. As 
already noted, the processes involved can be useful, but can also be co-opted defensively, i.e. in the attempt to avoid confrontation with reality. They change not only what we feel, but also what and how we think about the people or situations involved. The three examples given involve the defence mechanisms of projective identification, in which traits or 'parts' of the self are imaginatively projected into others; reversal, in which the subject and object of an emotion are switched around; and isolation, which strips away and represses the personal and emotional significance of an event. There are others. ${ }^{9}$

The anxiety that indicates the operation of defence mechanisms can, with difficulty, sensitivity, and practice, be introspectible in emotional self-awareness, registering as the feelings of tension and discomfort described above. We can, with self-knowledge, 'catch ourselves', but this self-awareness is not easy to achieve.

The relationship between the emotion that is felt and the anxiety can vary from case to case. Here are some illustrative examples:

1. the anxiety and emotion are the conscious manifestation is of an unconscious emotion that is being defended against. Changing our earlier example slightly, our resentful man is resentful around $\underline{a}$, who has achieved what he hasn't, because he is resentful of his parents, whom he blames for his lack of success. His anxiety, here, could indicate either the pain of this insight were he to realize why he is resentful, or his fear of taking responsibility for his life.

2. the anxiety is a conscious manifestation of the unconscious anxiety that instigated the defence mechanism, caused by a different unconscious emotion, while the conscious emotion is a product of the defence. The case of homophobia described above could exemplify this: the anxiety is the 
manifestation of the unconscious fear of one's own homosexual desire, while the aggressive rage is the result of projecting the object of fear into homosexuals.

3. the anxiety is that of realizing something truthful about oneself that does not live up to one's ideals. For example, my anger may make me feel anxious because I cannot accept that I care so much about the object of my anger. In this case, I might seek to represent my anger as devoid of reason, perhaps simply the product of a mood.

4. the anxiety is that of being cut off from one's emotions, for instance, if one fails to feel anything at all in a situation of personal significance.

What all these cases have in common is that an emotional experience is marked with anxiety (or other difficult, second-order emotions). In many of them, the emotion felt seeks to conceal the anxiety. And in each of them, if the subject is emotionally selfaware, he or she may be able to detect the anxiety that their emotional response, or absence of emotion, can conceal.

Since anxiety of this kind typically indicates the operation of defence mechanisms, exploring it together with the emotions we feel can enable insight into the sources of our emotions. Emotional self-awareness, which does not simply register the fact that we feel the emotion but also enables us to detect our anxiety about feeling the emotion, alerts us to the possibility of defensive responses. And this is clearly important for good deliberation; consider the resentful worker deliberating about whether to take another job, or the homophobe considering how to respond to the news that his son is homosexual. Emotions that are the product of defence mechanisms are not appropriate evaluative responses to the world. Emotional self- 
awareness enables us to detect our anxiety which raises the possibility that our emotional response to the situation is being driven by defence mechanisms. Focusing attention on the emotion threatens to expose its defensive nature: Is it concealing something? In other cases, in which an emotion challenges our self-image, the defensive response is to discount the significance of the emotion, which may be an appropriate evaluative response. Here, emotional self-awareness forewarns us of the possibility of defence mechanisms operating in how we respond to this painful truth

(for instance, ignoring it, denying it, isolating it, projecting it, etc.). In each case, unless we realise the nature of our feelings, we may not judge or decide well.

Of course, non-emotional self-awareness of the kind intellectualism advocates may also enquire into the sources of our emotions. Why isn't this enough?

\section{Insight and Intellectualization}

The main point of the last section is that without being alive to the feelings of anxiety and calm that characterize the presence or absence of defence mechanisms, our enquiry into the sources of our emotions loses a vital source of information. Being emotionally self-aware when we evaluate an emotion provides us with information which, at the very least, we would find much more difficult to access if we do not respond affectively. The following example illustrates this, as well as the need to be willing to question our emotions sensitively:

Let us assume that a wife is deeply disturbed at learning that her husband has had a transient affair with another woman. Even months later she cannot get over it, although she knows it is a matter of the past and although the husband does everything to re-establish a good relationship. She makes herself and him miserable, and now and then goes on a spree of bitter 
reproaches against him. There are a number of reasons that might explain why she feels and acts in this way, quite apart from a genuine hurt about the breach of confidence. It may have hurt her pride that the husband could be attached to anyone but herself. It may be intolerable to her that the husband could slip out from her control and domination. The incident may have touched off a dread of desertion ... She may be discontented with the marriage for reasons of which she is not aware, and she may use this conspicuous occurrence as an excuse for expressing all her repressed grievances ... She may have felt attracted toward another man and resent the fact that her husband indulged in a freedom that she had not allowed herself. If she examined such possibilities she might not only improve the situation considerably but also gain a much clearer knowledge of herself. ${ }^{10}$

If she did 'examine such possibilities', how could the woman decide between them? She might try to 'figure it out', but she may come to decide her anger is a matter of hurt pride when in fact it is dread of desertion. It seems that until the woman can feel the feelings the different hypotheses suggest, they lack confirmation, and any hypothesis will remain a hypothesis. The woman needs the willingness to feel and acknowledge whatever her emotions actually are. If there is another way of judging which explanation correctly identifies the source of her anger, it will certainly be more convoluted, interpretative, and open to doubt. So we may conclude that reason that is not informed and qualified by emotional self-awareness will not have the means to know of its 'insights' that they are insights - it cannot confirm their truth.

The complexity and subtlety of the sources of our emotions is obvious. Put simply, however, we need to know, in our evaluation of our emotions, whether an emotion is the product of a defence mechanism, and if so, what that defence mechanism is seeking to hide. To know which of several possible explanations we come up with is true, we need to engage openly with the thoughts and feelings we have. We must be prepared to actually feel; and if we are, then we shall feel whatever 
emotional responses (if any) we have, and emotions enter into our deliberation. For emotional self-awareness, we must add to this openness a willingness to reflect upon our emotions, to feel and explore our further 'second-order' responses to our emotions.

To all this, we may add the case against non-emotional self-awareness. The absence of any affective response when evaluating one's emotions suggests that something is awry. Without feeling both one's emotions and one's responses to one's emotions, it is highly questionable whether one is genuinely open to one's emotions. Not to engage with one's emotions emotionally suggests an unwillingness to fully engage with the emotions in the first place. This unwillingness requires explanation. One likely answer, based on what has been said above, is that one is trying to avoid feeling anxiety. Avoiding the affective force of one's emotions and one's secondorder responses to them is a tactic of the defence mechanism of intellectualization. So $\underline{\text { the absence of emotional self-awareness, precisely when one is attempting to }}$ understand and evaluate one's emotions, is indicative of a psychological defence.

Intellectualization defends against anxiety partly by working with denial, isolation, or repression to simply not feel the emotion that arouses anxiety, and partly by using various means of avoiding the emotion's implications and personal significance. ${ }^{11}$ It can defend against the feelings themselves or against recognizing the importance of whatever the feeling is a response to. For instance, it may defend against the anger I feel because this would bring to mind the injury that was done to me, and it is the injury, rather than the anger per se, that arouses pain or anxiety.

One particularly relevant way intellectualization can work is by shifting attention from the external stimulus that arouses feeling to thought processes themselves, using self-observation as a defence. The focus of attention onto thought 
acts to suppress feeling. Emotions are replaced by the second-order non-emotional registering of 'the fact that I feel $\mathrm{x}$ '. In place of the emotion is the intellectual, and isolated, 'fact' of the emotion (if the subject admits at all that they feel something). The value and personal significance registered directly by the emotion as an evaluative response to its object are no longer directly registered. In their place is a fact of psychology. The move strips the emotion of its feeling, so it is no longer felt. The move from feeling to non-emotional representation of the emotion is a defence against discomforting feeling and/or realizing something of significance.

So I claim that the substitution of the fact that one has a certain emotion for the emotion itself, a move central to non-emotional self-awareness, is evidence for the operation of a defence mechanism. And this is why a non-emotional self-awareness should be viewed with suspicion. Not feeling any emotion does not mean one's thinking is undistorted. Assessing one's emotions non-emotionally suggests an anxiety about feeling the emotions one is assessing and/or about what such feelings could reveal (either about the situation or oneself). Obviously, the reasons for this anxiety could prove very important for the results of deliberation.

The case against intellectualism, then, is this: Intellectualism advocates suppressing emotion during deliberation, and if emotion is to be evaluated, then it must advocate replacing emotion in thought by 'the fact that I feel x' in order for that evaluation to be conducted non-emotionally. Furthermore, if we substitute nonemotional self-awareness for emotional self-awareness, even if this is not a product of a defence mechanism, our evaluation of our emotions is more likely to be influenced by defence mechanisms - first, because it deprives us of a vital means of detecting the operation of defence mechanisms; and second, because the emotionless state of mind is subjectively indistinguishable from one that is produced by a defence mechanism. 
How can such deliberation avoid being co-opted by intellectualization, or tell if it is co-opted, if it is not already a reflection of it?

\section{$\underline{\text { IV. Objections }}$}

I shall consider four responses from the intellectualist. The most obvious, the fact that emotions can distort and disrupt our thinking, I shall deal with in the next section.

So, second, the intellectualist may protest that surely there are occasions when we simply do not have these further second-order responses of tension or calm. Even if this is true, it does not help intellectualism's cause. Unless one is highly aware of one's emotions, and this involves being open to the emotions that one does have, one cannot distinguish between being emotion-free and simply repressing or intellectualizing one's emotions.

Third, I have said that our experiences and interpretations of anxiety are not transparent or incorrigible. If I experience the positive feelings of emotional selfawareness, this is evidence for the absence of distortion in emotional response. But emotions that are genuinely responsive to values are not self-validating; nor do these experiences of feeling certain emotions without anxiety prove one right (not least because our ego-ideals can themselves be products of defence). So, it seems, it may be objected that emotional self-awareness is not going to make the decisions we reach any more secure or morally right.

This misses the point, which is that emotional self-awareness is central to good deliberation, which is first-personal. It cannot substitute for reasoned thought, but our experiences of anxiety and calm are, I have argued, of epistemological benefit. The best we can do as individuals, regarding getting value judgments right, is to bring 
reason together with emotions that feel genuinely appropriate and self-expressive, and bring these together with self-knowledge, which may identify further causes in our psychology that may account for some of these emotions. In any of this we may fail, but insofar as we succeed, those emotions that survive as genuine embody our view of things, the values we are ready to stand by.

Finally, what can I say of subjects, who taking on board all the points above about emotional self-awareness, conduct their deliberation in two stages: first, they are emotionally self-aware, noting the personal significance of their emotions and their propensity towards certain distorting defensive thoughts and feelings; then, for deliberation, they become non-emotional - 'cool' and 'clear-headed', to prevent emotions from influencing the course of the deliberation, while taking into account all that they have discovered during emotional self-awareness ${ }^{12}$ Wouldn't this ultimately vindicate intellectualism?

It would not, for during the process of deliberation, further feelings can arise providing more of the kind of information provided by emotional self-awareness in the first place. Even while attempting to bear one's feelings and propensities for distortion in mind as a list of facts about oneself, deliberation can go astray, and these propensities can operate unconsciously. Deliberation can still start to miss the point, and our thoughts can become distorted or unnecessarily technical; defence mechanisms can still operate even when we know they are likely to. The best we can hope for is to develop the ability to pick up when we become defensive. And if this occurs, deliberation which is emotionally disengaged will be less likely to pick it up. But if we are open to the feelings that indicate this, we have a better chance of catching ourselves. This is why deliberation that operates with just facts, even facts 
originally provided by emotional self-awareness, rather than engaging with the emotional dynamics of the self at the time, is fundamentally flawed.

Unless deliberation is constantly open to the feelings that arise during the process of reflection, it runs a greater risk of leaving unconscious influences on deliberation uncovered and unexplored. We cannot first evaluate our emotions in emotional self-awareness, and then close ourselves to feelings in order to evaluate them by 'non-emotional' reason. The process of evaluating our emotions involves both reason and emotional self-awareness, not sequentially, but together. Reason here is not emotionally cold. In order to evaluate our emotions reliably, we need to draw on the resources of emotional self-awareness.

What would be the temptation to adopt a two-stage strategy, anyway? Only a continued commitment to the idea that emotional thought is less reliable than unemotional thought - which I hope to have disproved by the discussion of intellectualization; or the concern that emotions have a propensity to be disruptive, a topic with which I shall end.

\section{$\underline{\text { V. Disruptive emotions }}$}

Intellectualism is at one with common-sense in holding that an emotion that seems to muddy the waters, to impede clear deliberation, to be unhelpful, to distort what we think, needs to be laid to one side so that deliberation can continue more rationally and productively. It is not impossible that this should be the right approach in some cases, for emotions can be genuinely destructive of deliberation. But cases differ, and we should note that to come to this conclusion one first needs to explore and understand the emotion, rather than lay it aside immediately. 
Repressing, ignoring, or disowning emotions that disrupt or distort thought does little to constructively engage with the mental states that underlie them and are likely to remain psychologically active even if the emotion is suppressed. Why it is that I feel this way is not altered by ignoring the feeling, and these grounds will continue to influence how I think in ways I may not recognise, something intellectualism fundamentally fails to recognise.

So there are two ways in which we may respond to and cope with a disruptive emotion. We may approach it either as an object of explanation, to be taken account of as a possible (and possibly illicit) influence on deliberation; or in the spirit of selfunderstanding. The first approach is in line with the replacement of an emotion by a fact of psychology. Objectifying an emotion is one way of psychologically disowning it, of being unprepared to grant it personal significance. And deliberating in ignorance of the personal meaning of the issue about which one deliberates is clearly unsatisfactory. The significance of the disruptive or distorting emotion is best incorporated into the process of deliberation. If my deliberation is shaped by significances I do not understand, the patterns my decisions take will not in fact match a plan of the good life as I understand it, even if I rationalize each decision as it happens. For I have not understood the significance of the situations that face me or the grounds of my 'choices', even if I deceive myself into believing that I have.

More productively, we can adopt a spirit of self-understanding. What needs to be taken into account is my feeling this emotion. It is I who stand in need of explanation. After all, the emotion has come up in connection with a topic of some importance to $\underline{\text { me}}$, since I am deliberating about it. I should be willing to attach personal meaning to the anomalous emotion. On this second approach, the first step is to engage with the emotion in emotional self-awareness as far as possible, feeling 
both the emotion and my responses to it and approaching it as part of myself. Doing so will increase my insight regarding the topic that aroused the emotion, revealing some significance that has hitherto remained unconscious.

But what of emotions that are felt too strongly for deliberation to proceed? Once we have understood the emotion as far as possible, it would seem that we must set it aside; and this is true at times. We can, if we need to, put the emotion aside, which may involve deliberately curbing the strength of the feeling so that thought can proceed more clearly. But the need to set aside or suppress an emotion completely may be rarer than the intellectualist is prone to imagine. For emotional self-awareness does not require that the emotion must be felt with its full force, but that it must be felt; that is to say, it must be represented in thought with an emotional sensitivity that re-presents and engages with its affect, not one that attempts to strip its affect from it. However, the emotional openness of emotional self-awareness can be detached, in that the emotion felt does not overwhelm the subject, but is moderated sufficiently to be questioned and understood, while still being engaged, for the emotion continues to be felt. (This applies both to the exploration of the significance of the feeling and the continuation of deliberation, for a powerful emotion can prevent both its own exploration and further thought, as the case of the angry woman in $\S$ III illustrated.)

This point regarding 'detached engagement' is central to a correct understanding of the claims of emotional self-awareness. The idea of feeling an emotion in this way is familiar from aesthetics. Wordsworth, for instance, claimed that poetry 'takes its origin from emotion recollected in tranquillity' ${ }^{13}$ which involves the poet feeling once more the emotion felt originally, though in a weaker form. What I am claiming is analogous. If an emotion is not distracting from deliberative thought, it can continue to be felt during reflection; if its affect impedes reflection, then it can 
be moderated by a detached-yet-engaged empathetic sensitivity to it; if it cannot be moderated, then of course, it must be set aside during deliberation or deliberation is not possible until the power of the feeling has passed a little. In being detached, and moderating the force of the emotion, it is important that there is no attempt to deny the personal significance of the feeling in any way. When we must moderate an emotion for deliberation to be proceed, it is only emotional self-awareness that accepts the emotion for what it is and learns from it.

Whether our emotion is appropriate or inappropriate, disruptive or not, the awareness of the existence, status, and nature of our emotions needs to be an emotionally responsive awareness. And so the evaluation of our emotions will involve second-order emotional responses. So intellectualism's claim that reason can and should autonomously and independently evaluate our emotional responses to situations is false. ${ }^{14}$

\section{$\underline{\text { Heythrop College }}$}

$\underline{\text { Kensington Square }}$

London W8 5HQ

\section{m.lacewing@heythrop.ac.uk}

\footnotetext{
${ }^{1}$ This view is now widespread. See Deigh, J. 'Cognitivism in the Theory of Emotion: A Survey Article', Ethics 104 (1994), pp. 824-854; Nussbaum, M. Upheavals of Thought (Cambridge: Cambridge University Press, 2001); Ben-Ze'ev, A. The Subtlety of Emotions (Cambridge: MIT Press, 2000); Cavell, M. The Psychoanalytic Mind (Cambridge: Harvard University Press, 1993); Damasio, A. Descartes' Error (New York: G.P. Putnam's Sons, 1994); Goldie, P. The Emotions (Oxford: Oxford University Press, 2000); Stocker, M. \& Hegeman, E. Valuing Emotions (Cambridge: Cambridge University Press, 1996).
} 
${ }^{2}$ See Smart's contribution to Smart and Williams, Utilitarianism: For and Against (Cambridge: Cambridge University Press, 1973), pp. 44, 73; Hare, R. Moral Thinking (Oxford: Clarendon Press, 1981), pp. v, 215, 218; Singer, P. How are We to Live (Amherst: Prometheus Books, 1995), pp. 153, 175, 225-233; Singer, P. 'Reasoning towards Utilitarianism' in Seanor \& Fotion, Hare and Critics (Oxford, Clarendon Press, 1988), p. 147, and Hare's response, p. 268; see also Unger, P. Living High and Letting Die (Oxford: Oxford University Press, 1996). Benevolence, the foundation of utilitarianism, has much of its emotive nature removed by abstraction; see Smart, pp. 31, 56; and

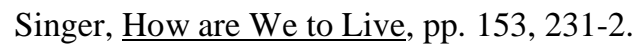

${ }^{3}$ Recent debates have tended to focus on the role of emotion in motivation and supererogation - see Baron, M. Kantian Ethics Almost Without Apology (Ithaca: Cornell University Press, 1995). ${ }^{4}$ See Nell, O. Acting on Principle (New York: Columbia University Press, 1975), Chh. 3, 6.

${ }^{5}$ Dancy, J. Moral Reasons (Oxford: Blackwell, 1993), Chh. 1-2, and p. 46; and Nagel, T. The Last Word (Oxford: Oxford University Press, 1986).

${ }^{6}$ See Freud, S. 'The Neuro-Psychoses of Defence' (1894), The Standard Edition of the Complete Psychological Works of Sigmund Freud (London: The Hogarth Press and The Institute of Psychoanalysis, 1953-74), Vol. III, 45-61; Freud, A. The Ego and the Mechanisms of Defence (London: The Hogarth Press, 1968); Bateman \& Holmes, Introduction to Psychoanalysis (London: Routledge, 1995).

${ }^{7}$ Gardner, S. Irrationality and the Philosophy of Psychoanalysis (Cambridge: Cambridge University Press, 1993), p. 145. The mechanisms operate by phantasy; see Isaacs, S. 'The nature and function of phantasy', International Journal of Psychoanalysis 29 (1948); Gardner, Ch. 6; Wollheim, R. The Thread of Life (Cambridge: Cambridge University Press, 1984), Chh. 4, 5.

${ }^{8}$ The term is Wollheim's; see op. cit., Ch. 2.

${ }^{9}$ See Bateman \& Holmes, p. 81.

${ }^{10}$ Horney, K. Self-Analysis, (London: Kegan Paul, Trench, Trubner \& Co., 1942), pp. 283-4

${ }^{11}$ See Kestenbaum, G. ‘Towards a Definition of Intellectualization', Psychoanalysis and Contemporary Thought 6 (1983), pp. 671-692.

${ }^{12}$ Thanks to Janice Thomas and Keith Horton for independently presenting this possibility to me.

${ }^{13}$ Wordsworth, W. 'Preface' in Wordsworth, W. \& Coleridge, S., Lyrical Ballads (Bristol, 1798) 
${ }^{14}$ Thanks to John Cottingham, Louise Braddock, Jim Hopkins, Janice Thomas, Keith Horton, and members of the London philosophy and psychoanalysis discussion group for their many helpful comments and suggestions. 